Editorial

\title{
Choice Meaning and Context: Two Sides of the Same Coin?
}

\author{
${ }^{1}$ Saadettin Sel, ${ }^{2}$ Joachim Storsberg, ${ }^{3}$ Mark A. Brown and ${ }^{4}$ Christian Schmidt \\ ${ }^{I}$ Department of Ophthalmology, University of Heidelberg, Heidelberg, Germany \\ ${ }^{2}$ Department of Biomaterials and Healthcare, Division of Life Science and Bioprocesses, \\ Fraunhofer Institute for Applied Polymer Research (IAP), Potsdam-Golm, Germany \\ ${ }^{3}$ Department of Clinical Sciences and Colorado School of Public Health, \\ Colorado State University, Fort Collins, CO, USA \\ ${ }^{4}$ Editorial Office, Am. J. Immunol., New York, NY, USA and Adelaide, SA, Australia
}

Article history
Received: 04-05-2017
Revised: 19-05-2017
Accepted: 24-05-2017
Corresponding Author:
Christian Schmidt
Editorial Office, Am. J.
Immunol., New York, NY,
USA and Adelaide, SA,
Australia
Email: schmidt102@gmail.com

\begin{abstract}
Understanding problems invariably hinges on a carefully written explication, based on experimental evidence or theoretical analysis, exact description of the phenomena, the experimental settings, as well considering existing precedent and advances over existing literature as presented in this report. As with any discourse, presenting all facets of the issue to be probed has become the cornerstone of the success of scholarly advance where fallacies and/or errors in the interpretation of the results can be traced and corrected at a later time, provided the record in question is available for scrutiny, preferably free of charge to the research community and the general public alike. Here, we draw on previous examples to reiterate the advantages of presenting seemingly adversarial points of view in a given study to allow future examination to be carried out in the proper context.
\end{abstract}

Keywords: Policy, Immunology
The human intellect is a powerful instrument to be applied to problems. Expressed differently, sharpening one's acumen by regular exposure to conundra can be likened to exercising a muscle or refining a tool such as creating brushes to suit certain tasks. Such applications hinge on a reasonable understanding of a given problem and the presentation of opposing viewpoints of the problem at hand, analogous to the presentation of counter-arguments in the judicial system or finding the synthesis from thesis and antithesis as in the Hegelian Dialectics.

Of note is that these modi of approaching a given problem have stood the test of time and proved to be practical solutions in the wider sense of the term. One can, perhaps, argue that such proven practices could be described as 'natural flowerings of behavior in its customary forms' (Scalia, 1989; 292 U.S. 98). Concordantly, scholarly writing, including discussing legal aspects of problems, benefit from a balanced view. We shall incorporate the points made elsewhere, including the references provided in Brown et al. (2016), as if they were stated here, to avoid repetition.

While we will not venture into the lingering enigma of why there is no enforceable right to Health Care in the
United States (Sandhu, 2007), a significant body of literature seems to be in support of the notion that, after fundamental requirements, such as housing and a steady supply of consumables are addressed, further growth of the economy can be linked to 'a more perfect Union' (Baltzell, 2013; Diener and Seligman, 2004). This notion is further supported by the recent enactment of the 21 st Century Cures Act underscores the apparent contradiction of views in legislation (Avorn and Kesselheim, 2015).

If indeed so, terms to describe the Constitution of the United States as 'adaptable to measures' (Ross, 2017) seem to be in stark contrast to the unchanged words of the Preamble of The Constitution, where 'in Order to form a more perfect Union' (Baltzell, 2013), the citizenry 'granting these powers for the public good' (17 U.S. 316).

It may perhaps be more opportune to call into question the meaning of terms at one time, such as the phrase 'more perfect Union'. Considering the abovedescribed 'natural flowerings of behavior in its customary forms' (Scalia, 1989; 292 U.S. 98), or, expressed alternatively by the term common sense, leaves little room to doubt that the Founding Fathers of The Constitution to the United States wished to 
leave a better world 'to [...] our Posterior' (Baltzell, 2013). In an unbroken line of reasoning to this day, no Supreme Court disagreed with the notion that 'No legislature can bargain away the public health or the public morals' (101 U.S. 814).

\section{Author's Contributions}

Mark A. Brown: Provided critical input and assisted in revising and improving the paper.

Saadettin Sel and Joachim Storsberg: Provided critical input and assisted in revising and improving the paper.

Christian Schmidt: Wrote the first draft of the paper, provided critical input and assisted in revising and improving the paper.

\section{Ethics}

Mark A. Brown, Joachim Storsberg, Saadettin Sel and Christian Schmidt: Report no conflicts of interest.

Mark A. Brown and Christian Schmidt: Are members of the Editorial Board of The American Journal of Immunology and are waived from the Article Processing fee for this contribution; both receive no remuneration, either individually or collectively, for their editorial work.

\section{References}

Avorn, J. and A.S. Kesselheim, 2015. The 21st century cures act-will it take us back in time? New England J. Med., 372: 2473-2475.

DOI: $10.1056 /$ NEJMp1506964

Baltzell, G. W. 2013. Constitution for the United Stateswe the people.

Brown, M.A., J. Storsberg and C. Schmidt, 2016. Where the future is being made today. Am. J. Immunol., 12: 17-19. DOI: 10.3844/ajisp.2016.17.19

Diener, E. and M.E. Seligman, 2004. Beyond money: Toward an economy of well-being. Psychol. Sci. Public Interest, 5: 1-33.

McCulloch v. Maryland, 17 U.S. 316 (1819)

Pokora v. Wabash Railway Co. 292 U.S. 98 (1934).

Ross, W.G., 2017. The enduring constitutional legacy of the first world war.

Scalia, A., 1989. The rule of law as a law of rules. Univ. Chicago Law Rev., 56: 1175-1188.

Sandhu, P.K., 2007. A legal right to health care: What can the United States learn from foreign models of health rights jurisprudence? California Law Rev., 95: 1151-1192. DOI: 10.15779/Z380M7R

Stone v. Mississippi 101 U.S. 814 (1879) 